\title{
Una hermenéutica de la cruz de Jesús desde el "realismo político"*
}

\author{
Loida Sardiñas Iglesias**
}

Recibido: 31 de marzo de 2015 • Aprobado: 10 de mayo de 2015

\section{Resumen}

En el contexto de un cristianismo afectado por el giro antropológico y el replanteamiento de la pregunta por el ser humano y su ser/estar en el mundo en la perspectiva de la humanización-deshumanización de la existencia, la lógica de justicia-injusticia social y la paradoja de la fe enfrentada al dolor y la miseria humanas, adquiere sentido preguntarse por la experiencia de fe en el Señor crucificado-muerto-resucitado. La teología de la cruz -staurología al interior de la teología sistemática-, que se inscribe en una tradición teológica crítica y a la vez, humanizante y esperanzadora, resulta un punto obligado para enfrentar las preguntas y paradojas del cristianismo occidental tardo-moderno. La cruz evoca provocación, locura, paradoja, sufrimiento, maldición, angustia, memoria anamnética; pero igualmente esperanza y criterio de discernimiento sobre la respuesta de Dios a la condición humana. Ella simboliza el escarnio y tortura de Cristo, la profundidad del sufrimiento de quien ante los ojos de romanos y judíos moría como rechazado, maldito de Dios y blasfemo. Condensa la imagen de aquel cristianismo triunfante y victorioso, que en el imaginario del gran poeta alemán Friedrich von Schiller se muestra como "religión de la cruz", adorno de tronos e imperios que con frecuencia en la Edad Media provocó el rechazo y la muerte. Pero el símbolo mismo de la cruz, la señal de la cruz y el crucifijo

* Producto de las investigaciones de la autora.

* La autora es médica y teóloga cubana, doctora en Teología por la Universidad de Hamburgo, Alemania y docente en el área de Teología Sistemática en el Centro de Formación Teológica de la Pontificia Universidad Javeriana, en Bogotá, Colombia. Correo electrónico: loidasardinas@gmail.com 
simbolizan también la fe y el culto de comunidades cristianas marginadas y clandestinas, la mirada y actitud orante, la piedad cristiana y la esperanza de salvación más allá del dolor y la finitud humanas.

Palabras clave: teología, cruz, sufrimiento, dolor, staurología.

\title{
A hermeneutics of the cross of Jesus from the "political realism"
}

\begin{abstract}
In the context of a Christianity affected by the anthropological turn and the rethinking of the question by the human being and his being/be in the world in the perspective of humanization-dehumanization of existence, the logic of social justice-injustice and the Faith paradox facing the pain and human misery makes sense to ask about the experience of faith in the Lord crucified-risen-resuscitated. The theology of the cross -staurology inside the systematic theology-, which is part of a critical theological tradition criticism and also, humanizing and hopeful, is an essential point to face questions and paradoxes of latemodern Western Christianity. The cross evokes provocation, insanity, paradox, suffering, curse, anxiety, anamnetic memory; but also hope and criterion of discernment of God's answer to the human condition. It symbolizes the ridicule and torture of Christ, the depth of suffering of those who in the eyes of Romans and Jews died as a rejected, cursed by God and blasphemous. It condenses the image of that triumphant and victorious Christianity, which in the imagination of the great German poet Friedrich von Schiller is displayed as "religion of the cross", motif of thrones and empires that often in the Middle Ages caused the rejection and death. But the very symbol of the cross, the sign of the cross and the crucifix also symbolize faith and worship of marginalized and clandestine Christian communities, the praying look and attitude, the Christian piety and the hope of salvation beyond the pain and human finitude.
\end{abstract}

Keywords: Theology, cross, suffering, pain, staurology. 


\section{Une herméneutique de la croix de Jésus depuis le "réalisme politique"}

\section{Résumé}

Dans le contexte du christianisme touché par la tournure anthropologique et de repenser la question de l'être humain et de son être dans le monde dans la perspective d'humanisationdéshumanisation de l'existence, la logique de la justice et de l'injustice sociale et la paradoxe de la foi face à la douleur et la misère humaine, $c^{\prime}$ est logique de se poser des questions sur l'expérience de la foi dans le Seigneur crucifié et ressuscité des morts-vivants. La théologie de la croix -staurologie au sein de la théologie systématique- qui s'inscrit dans une tradition théologique critique et au même temps humanisante et encourageante, est un point obligé pour faire face aux questions et paradoxes du christianisme occidental de la modernité tardive. La croix évoque la provocation, la folie, le paradoxe, la souffrance, la malédiction, l'anxiété, la mémoire anamnestique; mais aussi l'espoir et le critère de discernement de la réponse de Dieu à la condition humaine. Elle symbolise le mépris et la torture du Christ, la profondeur de la souffrance de celui qui, face aux yeux des Romains et Juifs mourait méprisé et maudit de Dieu et blasphème. Condense l'image du christianisme victorieux, que dans l'imagination du grand poète allemand Friedrich Von Schiller il est affiché comme «religion de la croix», ornement de trônes et empires que pendant le Moyen Age a souvent entraîné le rejet et la mort. Mais le symbole de la croix, le signe de la croix et le crucifix symbolisent aussi la foi et le culte des communautés chrétiennes marginalisées et clandestines, le regard et l'attitude de la prière, la piété chrétienne et l'espérance du salut au-delà de la douleur et la finitude humaine.

Mots-clés: Théologie, croix, souffrance, douleur, staurologie. 
Hubo un hombre que no sabía odiar; se dedicaba a hacer el bien a todos.

Su conducta se hizo primero extraña, luego escandalosa, por último insoportable. Una tarde apareció colgado entre el cielo y la tierra; no tenía figura humana.

La gente comentó: "pobrecillo, con lo bueno que era". $Y$ todos experimentaron una extraña sensación de alivio. ${ }^{1}$

(Sanz Arribas, 1999)

\section{Introducción}

El presente artículo se propone abordar esta ambigüedad y complejidad del acontecimiento de la cruz, desde una aproximación muy particular, que es la perspectiva bíblico-teológica del llamado "realismo político" como causa de la crucifixión de Jesús de Nazaret. Este abordaje pretende hacer eco a las propuestas de historización de la pasión de Jesús y a una comprensión del proceso histórico de la crucifixión del Crucificado en sintonía con la tradición de teología política y con la expresión cristológica que pone en su centro la pregunta por el Jesús histórico. Esto significa que la cruz será abordada ya no desde las clásicas reflexiones de la Teología especulativa de la pasión (soteriología, satisfacción, expiación, redención, sacrificio, etc.) o de la Teología espiritual de la cruz -también entendida como Pasiología del dolor -, que sitúan el misterio de la cruz y los padecimientos de Cristo en su martirio y muerte en cruz (passiones Christi) fundamentalmente en el ámbito de la piedad y mística del sufrimiento ${ }^{2}$, sino que se busca entender histórica y teológicamente el sentido de la cruz desde el acontecimiento en su propio origen e historicidad político-social. No se trata de una novedad en el estudio staurológico, pero sí de hacer de nuevo presente el pertinente retorno al

1 Poema de Sanz Arribas, A. citado por Blanco Pacheco, S. (1999) “¿Por qué y cómo murió Jesús?", Staurós 32: 5.

2 Para una aproximación al objeto de estudio de la pasiología, cf. Artola, A. M., (2011) La Pasiología (Roma: Editoriale Eco), p 98ss; De Mier, F. (1996) Teología de la cruz. Trípticos de las riquezas de la pasión (Madrid: San Pablo). 
"escándalo de la cruz" como vía de superación de visiones sacrificialistas de la cruz y de comprensiones edulcoradas de la teología de la cruz en tanto theologie glorie.

\section{Explicaciones a la simbólica de la cruz: religiosidad, culto, mística del dolor y seguimiento}

En el texto magistral, fundacional de la teología de la cruz dentro de la tradición de teología política alemana, El Dios crucificado. La cruz de Cristo como base y crítica de la teología cristiana, Jürgen Moltmann hace un recuento de aquellas explicaciones que sobre la cruz y su significado han venido apareciendo a lo largo de la historia de la Iglesia y del pensamiento cristiano. Con el objeto de mostrar que la cruz se resiste a una explicación unívoca desde criterios meramente humanos, el teólogo alemán contemporáneo realiza un importante análisis de las diversas tradiciones interpretativas de la cruz, dentro de las cuales se pretende resaltar, la cruz religiosa, el culto de la cruz con su resignificación del concepto de sacrificio, la mística de la cruz y la cruz como seguimiento. Una mirada rápida a estas explicaciones de la cruz nos permite comprender no sólo la centralidad de la cruz en la teología a través de sus interpretaciones históricas y contextuales y la vinculación intrínseca de la fe cristiana con el conocimiento del Crucificado, sino también abordar las ambigüedades y paradojas propias de la simbólica y hermenéuticas de la cruz.

En primer lugar, Moltmann cuestiona las representaciones románticas y religiosas de la cruz a lo largo de la historia de la tradición cristiana occidental, tal como se muestra en el propio símbolo de la "cruz de rosas" presente en el escudo de Lutero. En general se trata de representaciones de la cruz -plenas en flores, pulcritud, pureza, blancura, belleza, alegría- que han trastocado radicalmente el objeto de castigo y escarnio de Cristo y lo han despojado de su skandalon, desnudez y dureza, para transformarlo en "agradable" y salvador. En ese contexto el autor cita un texto del también teólogo luterano alemán Hans Joachim Iwand:

La cruz es lo absolutamente inconmensurable en la revelación de Dios. Nos hemos acostumbrado demasiado a ella. El escándalo de la cruz lo hemos adornado con rosas. Hemos hecho de ella una teoría de la salvación. Pero eso no es la cruz. Esto no es la dureza que en ella hay, la dureza que en ella ha puesto Dios. [...] Frente a la "palabra de la cruz" no contamos más que con la sola fide, como ante ninguna otra realidad 
del mundo. [...] Nuestra fe comienza en esa dureza y poderío que es la noche de la cruz, del abandono, del ataque y de la duda de todo cuanto existe. Nuestra fe tiene que nacer donde todos los hechos la abandonan; tiene que nacer de la nada, tiene que gustar y saborear esa nada (Moltmann, 2010).

Se trata de la crítica a una visión gloriosa de la fe cristiana, que elimina, invierte y vacía de sentido la propia realidad -Wirklichkeit y Realität- de la cruz, el escándalo, la injusticia y dolor que condensa. Para Moltmann se trata aquí de la necesidad de una mirada más histórica del acontecimiento que está en el origen de la cruz: el Cristo, el "Dios crucificado". Porque el "misterio" insondable de la cruz descansa justamente en esa capacidad de la cruz de articular la desnudez y dureza que ella muestra con la esperanza soteriológica que representa. Una aproximación tradicional a la cruz únicamente como signo de salvación, reduce la propia cruz y anula el encuentro con el Dios que se solidariza con la humanidad, se hominiza y recibe, en el marco de esta opción de humanización, una muerte cruenta. La cruz desde esta perspectiva, no es tan "natural" y gloriosa como hace parecer la tradición cristiana: "la cruz en la iglesia simboliza una contradicción que se adentra en ella a partir del Dios que fue crucificado "fuera". [...] El símbolo de la cruz en la iglesia remite al Dios que fue crucificado no entre dos candeleros sobre un altar, sino entre dos ladrones en el Calvario de los perdidos" (Moltmann, 2010).

Lo anterior introduce una segunda crítica a las explicaciones clásicas de la cruz en el ámbito litúrgico y cultual. Moltmann cuestiona el "culto a la cruz" en tanto representación eucarística del suceso del Gólgota y las interpretaciones sacrificialistas que de este culto se desprenden. Ubica el sacrificio humano de sí mismo y la autoentrega, orientado a satisfacer la necesidad del agrado y apoyo de los poderes y deidades trascendentes, en los orígenes mismos de la humanidad y las religiones. Y si bien la iglesia cristiana primitiva renunció y rechazó los actos sacrificiales en el marco de las antiguas religiones sacrificiales, de facto, se continuó en la tradición cristiana con una visión ambigua de la cruz como acto sacrificial y de la Eucaristía como sacrificio, aun cuando la muerte de Jesús no tenga una expresión cultual per sé: no se realiza en el templo, no está "oficiada" por un sacerdote, ni sigue un patrón ritual ${ }^{3}$. Desde esta perspectiva, el Crucificado es

3 Sobre este aspecto resulta sumamente interesante y esclarecedor la afirmación del teólogo Karl Rahner, en su Curso fundamental sobre la fe. Introducción al concepto de cristianismo: 
ahistorizado y abstraído de sus condiciones concretas de muerte para entenderlo como autodonación sacrificial instituida por el propio Dios para la salvación del mundo.

En tercer lugar y siguiendo con la dialéctica de aceptación-rechazo subyacente a las concepciones de la cruz, el autor recuerda que en el cristianismo histórico la pasión de Cristo fue comprendida y celebrada como mística de la pasión, la aflicción y el sufrimiento, asociada frecuentemente a los sufrimientos personales. Este camino, explorado por la mística medieval tardía, buscaba sumergirse, comunicarse y compenetrarse en la experiencia del sufrimiento de Cristo mediante la inmersión en los propios sufrimientos y dolores, lo que fue conocido como "conformidad espiritual con el Cristo crucificado" (conformitas crucis). La iglesia cristiana terminó convirtiendo la mística del dolor en una justificación del sufrimiento, siendo evidente que algunas visiones introyectadas en la piedad religiosa han contribuido a legitimar el suplicio y sufrimiento humanos. La comprensión del Crucificado en tanto sufriente ejemplar, quien abre el camino para que otros -los abandonados- también soporten y asuman su propia agonía; la comunión verdadera con Cristo como la experiencia de "su" dolor; la aceptación acriteriada de las "cruces" y sufrimientos propios, y la tácita imposición de aceptar y no rebelarse frente al sufrimiento, sobre todo cuando se trata del sufrimiento de los más desfavorecidos (pobres, enfermos, campesinos, esclavos) a lo largo de la historia del cristianismo, constituyen señales de esta mística del dolor transformada en justificación del mismo.

Por último, Moltmann recoge una cuarta explicación dada a la cruz a partir del seguimiento. A diferencia de la iglesia medieval practicante del sufrimiento pasivo del Crucificado, la iglesia moderna ha transitado en alguna medida, según el autor, por la vía del seguimiento activo -incluso martirial, de ser necesario-del Crucificado. La cruz aparece como el lugar teológico del seguimiento y el compromiso cristianos, lejos de las posturas acomodaticias burguesas modernas: el compromiso con las causas sociales, la opción por los pobres, el enfrentamiento de la intolerancia religiosa y el martirio, son algunas aristas de ello. Una lectura detenida de los evangelios indica los términos de este seguimiento de la cruz en

\footnotetext{
“El problema dogmático del concepto de sacrificio consiste en desarrollar un concepto tal de sacrificio, que tenga en cuenta, por una parte, los datos de la historia general de las religiones y, por otra, que sea aplicable tanto al 'sacrificio' de Cristo en la cruz, así como a la misa como 'sacrificio', sin violentar estos dos sacrificios neotestamentarios". E igualmente el aporte crítico de José Comblin sobre el concepto bíblico del sacrificio en "El sacrificio en la teología cristiana" en PASOS 96 (2001): 2-12.
} 
la primitiva comunidad cristiana como rechazo, incomprensión, renuncia a todo poder, persecución del apostolado, en aras de seguir y hacer presente el Reino de Dios predicado por Jesús. En términos de la teología sinóptica, joánica y paulina, el creyente que ha sido crucificado junto con Jesús, no se acomoda al esquema y las estructuras de este mundo ${ }^{4}$ (Rom 12,1); renuncia, muere y es crucificado junto a Cristo para el mundo (Gal 6,14). Esta renuncia al mundo y el seguimiento resultante ya no serían una pretensión de semejanza mística imitativa de Cristo:

El seguimiento acontece mediante la propia responsabilidad respecto de la misión de Cristo hoy y cargando con la propia cruz. Seguimiento de Cristo significa fe y este es, de hecho, una unidad existencial de teoría y praxis, como puede verse en la existencia apostólica y en la de los mártires (Moltmann, 2010).

Estas cuatro aproximaciones y expresiones históricas a la perspectiva de la cruz ayudan a descubrir representaciones diversas -y no exentas de ambigüedades-, del significado teórico y práctico de la cruz de Cristo. Pero sobre todo, la visión de conjunto sobre las explicaciones tradicionales de la cruz apuntan a la necesidad de traspasar el significante para acceder a su referente: al quid de la teología de la cruz que es el propio Crucificado. Mantener la fe en el Crucificado, seguir al Crucificado e intentar ser coherentes con la alegre y buena noticia de su Reino, implica volver la mirada a la encarnación y humanización del Logos, a su muerte y resurrección ${ }^{5}$. Significa reconocer, en términos de una historia de la salvación que sólo puede ser intrahistórica, que Dios se hominiza y se solidariza en la desnudez y dureza de la cruz, con la humanidad sufriente. Desde esta perspectiva, la cruz no es evocación de un evento religioso, cultural, sacrificial-fecundo,

4 En el Nuevo Testamento la palabra "mundo" puede incluir alguna de las siguientes acepciones: (a) mundo físico, universo, tierra (kosmos); (b) la humanidad que habita la tierra; (c) un grupo humano numeroso ("todo el mundo"). Sin embargo, en la perspectiva que nos interesa de la teología de la cruz, resulta obvia su utilización en tanto realidad del pecado, de los poderes, la ley y la muerte, en donde se evidencia "un orden socio-religioso enemigo de Dios. [...] El 'jefe del mundo' o 'del orden este' es una personificación del círculo de poder que rige 'el mundo', en su acepción del orden socio-político injusto donde están encuadrados los hombres" en, Juan Mateos y Juan Barreto, Vocabulario teológico del Evangelio de Juan (Madrid: Cristiandad, 1980), 312.

5 Lo que Moltmann expresa y condensa en los siguientes términos: “La fe cristiana está indisolublemente unida al conocimiento del Crucificado, es decir, al conocimiento de Dios en el Cristo crucificado o, para decirlo todavía más precisamente con Lutero: al conocimiento del 'Dios crucificado'”' (Ibíd., 102). 
glorioso y mítico, sino de un acontecimiento salvador que se origina en el hecho histórico de la crucifixión del Crucificado (Moltmann, 2010).

\section{La cruz como realidad de orden histórico y político}

Atender a los aciertos y desaciertos de las explicaciones teológico-especulativas de la cruz a lo largo de la historia de las ideas cristianas, obliga a la teología a esclarecer históricamente el acontecimiento histórico de la cruz y en ello, las causas reales de la muerte del Crucificado. Resulta obvio que cualquiera de las aproximaciones y explicaciones anteriores no constituyen constataciones teológicas neutrales y que todas ellas están cargadas de interpretación y sentido; han sido teologizadas, pensadas y/ o experimentadas en contextos epocales e históricos particulares y responden también a coyunturas teológicas, sociales, culturales y políticas específicas.

Frente a estas interpretaciones no neutrales de los relatos de la pasión y la cruz en los evangelios y la historia de la teología y el pensamiento cristianos el también teólogo de Heidelberg, Gerd Theissen en su libro El Jesús histórico, plantea la necesidad de esclarecer históricamente y desdogmatizar metodológicamente la cruz.

Sólo es posible acceder a la realidad histórica mediante la investigación crítica y la reconstrucción histórica (objetiva). Si lo que puede descubrirse como probable, una vez descontadas las tendencias de las fuentes, concuerda con lo que era posible históricamente, quizás no estemos lejos de la verdad histórica. [...] De ahí la necesidad de analizar la "tendencia" de las fuentes y delimitar los problemas históricos en cuestiones más concretas (Theissen, 2004).

La pretensión de reconstrucción histórica objetiva implica desplazar las categorías y explicaciones esencialmente teológicas especulativas para ir al hecho concreto, como proceso de desdogmatización de la cruz de Jesucristo. En otras palabras, conlleva poner el acento, la mirada y el interés investigativo en el proceso histórico que llevó a la muerte del Crucificado en los propios evangelios, los cuales asumen la muerte de Jesús explicitando las situaciones y argumentos históricos -fuentes, motivos, ideas, actores- y no desde una perspectiva meramente kerigmática, cultual, parenética y soteriológica del acontecimiento de la cruz. En este sentido, Theissen asume el análisis de la pasión desde los actores y 
protagonistas históricos del proceso, tomando en cuenta el rol jugado por (1) el poder romano, (2) la aristocracia judía local y (3) el pueblo judío, y lo hace a través del análisis de los aspectos histórico-jurídicos formales, las razones y los móviles reales del proceso, buscando su relación y fundamento objetivo en la vida del Jesús histórico, lo que se sintetizará en lo que sigue.

1. Para el autor alemán, no sobra preguntarse si los romanos crucificaron a Jesús por razones políticas o simplemente cumplieron con una sentencia dictada por el Sanedrín, siendo ellos -de facto, no de iure-nada más que un órgano ejecutor. En cuanto a sus motivos, la muerte de Jesús no podría tener otra causa más que en una acusación de orden político, en tanto Jesús pretendiera alzarse como rey de los judíos, lo que plantea la pregunta en Theissen por la historicidad del rótulo de la cruz de "rey de los judíos". Hay que tomar en cuenta que en su formulación el titulus crucis fue redactado desde una óptica eminentemente romana (Mc 15, 26) y que los judíos que hacen mofa de Jesús no asumen ni utilizan en su hablar el título de "rey de los judíos", sino que se burlan del "Cristo, rey de Israel" (Mc 15, 32). Esta acusación de orden político tendría consecuencias directas sobre Jesús por su significado como (1) ataque grave al país, y (2) daño al prestigio del pueblo romano y sus mandatarios. Respondiendo a lo anterior, el autor lanza hipótesis acerca de si Jesús aceptó o usó para sí el título rey de los judíos o solamente le fue atribuido por otros; de si fue un rebelde político, como afirma la tesis zelota o si los romanos fueron víctimas de un error cuando crucificaron a Jesús por pretendiente a Mesías. En cualquier caso, la crucifixión como pena de muerte sólo era aplicada a esclavos y sediciosos y la competencia para dictarla (ius gladii) estaba reservada a los romanos, quienes no delegaban la jurisdicción de la pena capital a las provincias, aun cuando podrían incluir un tribunal y la colaboración de otras instancias no romanas (cf. Jn 18, 31).

2. Respecto a la aristocracia local judía, Theissen discute su participación en el proceso histórico-jurídico que llevó a la muerte de Jesús en la cruz: en Marcos y Mateo se narra este hecho como si se tratara de un proceso con sentencia de muerte ante el Sanedrín, lo que suscita la pregunta por la legalidad o ilegalidad del proceso contra Jesús, antes elucidada; Lucas y Juan no incluyen este dato y se limitan a señalar el interrogatorio ante el consejo judío (Theissen, 2004). Theissen plantea la cuestión de si los judíos poseían facultades y competencias para dictar 
sentencias de muerte, tesis defendida por J. Blinzler quien asegura que en tiempo de Jesús existía el derecho saduceo en el procedimiento ante el Sanedrín, el cual dependía del prefecto romano (Theissen, 2004). Los motivos por parte de la aristocracia judía pueden ser aclarados desde razones pragmáticas y teológicas. En primer lugar, pudieron ver a Jesús como un peligro político como queda expuesto en Jn 11, 48: “Si lo dejamos seguir así, todos creerán en él, entonces vendrán los romanos y nos destruirán el santuario y la nación". Por otro lado, el consenso de los exégetas se orienta a afirmar que este temor por parte de los judíos encuentra su sustrato en el mensaje y actuación de Jesús, siendo sus convicciones teológicas las que precipitan la condena por parte de las élites religiosas judías. La acusación como blasfemo, su polémica respecto del templo, su inobservancia de la ley, de las prohibiciones sabáticas, y de las festividades religiosas, la pretensión mesiánica, etc., resultan temas neurálgicos para la mentalidad religiosa judía y sin duda, constituyeron factores desencadenantes y agravantes de la condena de Jesús, a lo que se volverá más tarde.

3. Por último, y con referencia al pueblo judío ${ }^{6}$ y ya no a su liderazgo político-religioso, Theissen señala que el protagonismo del pueblo no puede ser desvinculado de la condena a Jesús, ya sea en una función protectora o condenatoria. En este sentido habría que distinguir entre el pueblo jerosolimitano, ajeno y extraño a la propuesta y praxis de Jesús e imbuido en las dinámicas oficialistas del centro político y religioso que es Jerusalén, y el pueblo eminentemente campesino de la región de Galilea, seguidor de la praxis de Jesús y oidor de su mensaje. Por temor a este pueblo es que las autoridades deciden sentenciar y ajusticiar a Jesús antes de la fiesta de la pascua (Mc 14,1). La paradoja que se hace evidente es que el pueblo jerosolimitano resulta determinante en su condena, lo que se manifiesta en las posturas contradictoras entre la condena a Jesús y la escogencia y liberación de Barrabás. Es probable

6 Pueblo judío aparece aquí no en su acepción cultural referida a la identidad específica judía en tiempos de Jesús, con particularidades de expresión, lengua, religión, simbología, visiones de mundo, etc. La referencia y distinción del uso aquí, a diferencia de esta perspectiva antropológico-cultural y demográfica donde también estaría incluida la aristocracia judía, es (1) la sociológica, en tanto comunidad social colectiva que designa actores sociales cuyas acciones provocan efectos sociales (pueblo social) y (2) la económica, que remite a las capas más humildes y exentas de poder que conforman las amplias mayorías sociales de una nación, en este caso la judía. 
entonces que la simpatía popular de que gozara Jesús se condensase únicamente en los sectores y comunidades galileas y en los grupos mesiánicos que habrían depositado sus esperanzas en Jesús.

Resumiendo, el rol jugado por los actores involucrados en el proceso de Jesús, sean romanos, líderes políticos y religiosos judíos o el pueblo jerosolimitano y galileo, evidencia un común denominador en su actuación: la muerte del Crucificado se realiza con pleno conocimiento de causa, sopesando las situaciones y variantes que se presentaron y en observancia de las leyes y códigos civiles romanos o religiosos judíos vigentes.

Las convicciones teológicas y la conducta de Jesús representan un riesgo para el poder político romano y para el sistema religioso judío, en tanto es visto como una influencia subversiva negativa para el pueblo. Y a partir de la introyección del peligro que Jesús representaba, por parte de las mentes romanas o judías, es que el hombre Jesús es asesinado injustamente. Por ello, más allá de la aproximación theisseana, conviene mostrar a Jesús como un actante no ajeno a esta condena: él es el procesado y ejecutado y por tanto, resulta partícipe y protagonista en su propio proceso. La pregunta obligada es cómo participó y vivenció Jesús su sentencia de culpabilidad por incitación a la rebeldía y pretensión mesiánica y su ejecución por crucifixión, siendo que éstas se producen a consecuencia de su vida y praxis. El teólogo brasileño Leonardo Boff en su libro Pasión de Cristo - Pasión del Mundo, se pregunta si Jesús contaba con esta condena y muerte violenta:

Quien planteaba las exigencias que él planteó, quien cuestionaba la ley y el sentido del culto y del templo en función de una verdad más profunda, quien entusiasmaba a las masas empleando en su proclamación palabras densas de contenido ideológico (Reino de Dios, violencia), podía y debía contar con la reacción de los mantenedores del orden de aquel tiempo: los fariseos (la ley), los saduceos (el culto en el templo) y los romanos (las fuerzas de la ocupación política) (Boff, 1980).

El juicio, condena y ejecución por traición por parte del procurador Poncio Pilato, que resulta quizás el hecho más probado de la vida pública de Jesús por la literatura y fuentes extrabíblicas ${ }^{7}$, condensa una acusación que tiene eviden-

7 Documentos no cristianos que certifican la condena y muerte de Jesús pueden referenciarse en Suetonio, Tácito, Plinio el Joven, Flavio Josefo, entre otros filósofos e historiadores antiguos. En Anales, Tácito comenta: “El autor de este nombre fue Cristo, el cual, imperando 
te matiz político: “Comenzaron a acusarle diciendo: 'Hemos encontrado a éste alborotando a nuestro pueblo, prohibiendo pagar tributos al César y diciendo que él es Cristo Rey'." (Lc 23, 2). Concordando con Boff en las exigencias y cuestionamientos asumidos por Jesús durante su predicación y ministerio público, habría que buscar entender el carácter de tal predicación desde el punto de vista político. En otras palabras, preguntarnos si realmente Jesús incitó al pueblo a la rebelión, se opuso al pago de tributos, pretendió ser quien gobernase a los judíos o hizo planes para derrocar al gobierno. Aquí aparecen posiciones encontradas (Nolan, 2011). Por un lado, algunos autores afirman que Jesús estuvo altamente implicado en las discusiones y acciones políticas de su época, que entre sus discípulos se encontraba el zelote Simón (Lc 6, 15; Hch 1, 13), y que incluso Pedro, Judas o los hijos de Zebedeo también eran zelotes. Por otro lado, tradicionalmente se ha afirmado la inocencia de Jesús respecto de tales acusaciones políticas, argumentándose que no fue un incitador a la rebelión, recomendó pagar los impuestos y fue eminentemente pacifista, enfatizándose con esto una visión de Jesús como líder espiritual y religioso.

Frente a estas posturas habría que asumir una posición intermedia, dado que para la mentalidad judía no existe una división tajante entre política y religión, entre lo secular y religioso, entre lo profano y lo divino, sino que toda problemática entendida fragmentariamente hoy como política, económica, social, cultura o religiosa, era concebida y abordada de una forma integral referida a la realidad de Dios y su revelación histórica en medio de su pueblo. Esto no obvia la existencia de cuestiones epocales políticas, pero articuladas y referidas a su religión, y en este sentido, a la manera de las relaciones con el imperio y la dominación romana, concebidas como problemas político-religiosos. Jesús no era ajeno a estas problemáticas, y deseaba, lo mismo que los zelotes y cualquier judío, la liberación de la provincia de Judea. La dificultad existente para evidenciar sus posiciones políticas radica en el hecho que los evangelistas no se mostraran interesados en este tipo de afirmaciones, por su ubicación no palestinense y por su temporalidad posterior a la caída de Jerusalén, cuando con alta probabilidad no era de interés para nadie este tema (Nolan, 2011). Sin embargo, el documento que está a la base del evangelio lucano conocido como el Proto-Lucas, referenciado por el teólogo neotestamentario Paul Feine, relaciona a Jesús con personas

Tiberio, había sido ajusticiado por orden de Poncio Pilato, procurador de Judea" (http://www. antorcha.net/biblioteca_virtual/historia/tacito/15a.html). 
y expresiones vinculadas a la liberación política y a la salvación de Israel de sus enemigos políticos ${ }^{8}$.

Ahora bien, la liberación política del dominio romano que Jesús proponía no era idéntica a la propuesta por el nacionalismo judío impulsado por los zelotes y otros grupos políticos; ella se inscribe en la tradición de la predicación y denuncia político-religiosa profética. Jesús intentó sensibilizar, persuadir, convertir mucho más profundamente a Israel desde una transformación de la mente, el corazón y la vida, sin la cual no sería posible lograr ninguna otra liberación fuese imperial, religiosa o económica. La lectura de los signos de los tiempos, el discernimiento de los cambios necesarios, la reconciliación, la solidaridad, la compasión y el amor a los enemigos como postura ética radical, no opcional sino obligante, la aceptación del proyecto del Reino de Dios no excluyente y siempre abierto en tanto don y gratuidad, y la búsqueda de una libertad que los hiciese verdadera y auténticamente libre de la ley, del poder, del dinero, del prestigio, constituyen signos de una predicación liberadora de todos los aspectos fundamentales de la vida por parte de Jesús. Centró su mensaje en la crítica a aquellas estructuras socio-políticas, religiosas y legales que tenían que ver más con el tipo de judaísmo imperante y su exposición y validación por parte de la aristocracia judía (fariseos, escribas, sacerdotes) que con la expresión política romana. Lo que magistralmente señala el teólogo uruguayo Juan Luis Segundo en Liberación de la Teología:

La opresión concreta, diaria, estructurada, a la que se enfrentó Jesús, en su tiempo no aparecía como "política" - en el sentido moderno de la palabra -, sino más bien como "religiosa". Quienes determinaban la estructura sociopolítica de Israel eran, más que los empleados del Imperio, la autoridad religiosa de escribas, fariseos y saduceos. Que Jesús haya hecho trizas esa autoridad realmente política, lo prueba el hecho de que el interés por eliminar físicamente a Jesús, en cuanto amenaza para el status quo, viniera, no de los representantes del Imperio Romano, que sólo dieron un aval desinteresado y formal, sino de las autoridades supuestamente "religiosas".

Y más adelante,

8 La investigación de Feine sobre el Proto-Lucas aparece en alemán en 1891 bajo el título Eine vorkanonische Überlieferung des Lukas y es reseñada por A. Nolan, Ibíd., 153ss. 
La vida política, la organización cívica de las masas del pueblo judío, sus cargas, su opresión dependían mucho menos del Imperio Romano y mucho más de la teología vigente entre los escribas y los fariseos. Estos, y no el imperio, eran los que imponían cargas intolerables a los débiles estableciendo con ello la verdadera estructura socio-política de Israel [...]. Tan es así, que la contra-teología de Jesús era mucho más política de lo que habría, sino posible pronunciamientos o acciones contra el Imperio romano (Segundo, 1975).

De cara al proceso, sentencia y muerte que sufre Jesús, es posible entonces afirmar un contenido profunda y radicalmente teológico-religioso-político en la crítica a los poderes dominantes presente en la predicación de Jesús que coadyuva su condena, aun cuando la mediación y el lenguaje no sean directamente políticos, quedando evidenciada la falsedad, inversión y manipulación de las acusaciones. Jesús no busca este tipo de acusación en su contra, ni su muerte; sino que persigue la predicación y la irrupción del reino, aún conociendo la suerte de los profetas en Israel y estando dispuesto a ser consecuente hasta sus últimas consecuencias; actúa con plena libertad, enfrentando los poderes de este mundo y siendo consciente del peligro que significa su predicación para su propia vida.

(La muerte) le vino impuesta por una coyuntura que se había ido formando y de la que no había otra salida digna si no quería traicionar su misión. La muerte fue la consecuencia de una vida y de un juicio acerca de la cualidad religiosa y política de la misma vida. Él no la buscó ni la quiso; tuvo que aceptarla. Y la aceptó, no con impotente resignación y soberano estoicismo, sino como un ser libre que se sobrepone a la dureza de la necesidad. No deja que le quiten la vida sino que él mismo, libremente, la entrega, como se había entregado durante toda la vida. [...] En función de este mensaje y de la praxis que implica estaría dispuesto a sacrificarlo todo, incluida la vida. Si la verdad que proclama, atestigua y vive le exige morir, acepta la muerte. No porque la busque por sí misma, sino porque es la consecuencia de una lealtad y fidelidad que es más fuerte que la muerte (Boff, 1980). 


\section{El "realismo político" en la muerte de Jesús}

A partir de la lectura de orden histórico-sistemático aportada por Jürgen Moltmann y las consideraciones generales bíblico-históricas asumidas desde Gerd Theissen, Albert Nolan y Leonardo Boff se busca en lo que sigue, abrir el espacio para una consideración de la condena y asesinato en cruz del Crucificado desde el "realismo político" ${ }^{\text {, }}$ que devuelva a la cruz su carácter escandaloso. Se trata de evidenciar en la muerte de Jesús los criterios y acciones de la "realpolitik", guiados por intereses prácticos y necesidades inmediatas que no dan cabida a los principios teóricos y a la ética política por parte de los actores y protagonistas del quehacer político presentes en la muerte de Jesús (romanos y aristocracia judía). El skandalon de la cruz se hace evidente desde el horizonte y significado histórico de una muerte y asesinato injusto que es legitimado y perpetrado por actores y estructuras políticas legalistas y religiosas que se mueven por lógicas y racionalidades inmediatistas. Esta hipótesis será explorada, en diálogo con la tradición de teología política alemana, y a partir de la crítica a la sacrificialidad, el legalismo, y el cálculo político presente en la obra del teólogo y economista alemán Franz Hinkelammert. No se tratará, en estas pocas páginas y como en el caso de Moltmann y Theissen, de una exposición y discusión detallada de conceptos y argumentaciones presentes en este autor, sino únicamente se pretende traer a colación algunos aportes en la línea de la teología de la cruz, en la perspectiva de una historización de la muerte del Crucificado.

En una aproximación teológica sin pretensión exegética al Evangelio de Juan, presente en su libro El grito del sujeto. Del teatro-mundo del evangelio de Juan al perro-mundo de la globalización, Hinkelammert expone la interrelación entre las transgresiones de la ley por parte de Jesús y el relato de la pasión en este evangelio. Lo que se ha expresado con anterioridad como la condensación en el ministerio público de Jesús de una propuesta por el Reino de Dios, aparece ante los

9 La expresión "realpolitik" - también conocida como "política de realidad" o concepción realista de la política -, comienza a usarse en Alemania a mediados del siglo XIX para explicar aquellas posturas políticas que se rigen por criterios pragmatistas para medir el éxito político. A lo largo de la historia de las ideas políticas y filosóficas, aun cuando ha predominado cierta vaguedad conceptual en su teorización, se logra distinguir su génesis en autores de la "razón de estado" como Nicolás Maquiavelo, Baruc Spinoza y Thomas Hobbes. La expresión ha sido utilizada "para denotar el matiz analítico y conjetural (en desmedro del meramente normativo) que tenían las reflexiones sobre el comportamiento efectivo - es decir, histórico y concreto - de los actores políticos". Luis R. Oro Tapia, "En torno a la noción de realismo político", en Enfoques, Vol VII, 10 (2009): 15-46, en http://redalyc.uaemex.mx/pdf/960/96012388003.pdf. 
ojos de los tres actores -romanos, aristocracia judía y pueblo- como transgresión a la ley, en una expresión no particularizada ni accidental, sino principista. No se trata de transgresiones coyunturales a normas específicas, lo que también se produce en Jesús y sus discípulos, sino del hecho de que Jesús rehúsa aceptar la legitimidad por legalidad de la ley, lo que el autor llama "la negación de la validez a priori de la ley":

Ciertamente no hay una simple transgresión de la Ley sino una negación de la validez a priori de ésta en cuanto legalismo de una norma. En cuanto que el pensamiento sobre la Ley de aquellos que se enfrentan a Jesús es legalista es este sentido, la actitud de Jesús resulta ser de rebeldía a la Ley y, en cuanto que la Ley es Ley de Dios, de blasfemia. Activan frente a Jesús todo el "peso de la Ley", que no es el peso de alguna ley específica cuestionada sino de la Ley, y por consiguiente de la legalidad como tal. Donde desde el punto de vista del sujeto humano se comete pecado por cumplimiento de la Ley, desde el punto de vista del legalismo de la Ley este sujeto humano rebelde aparece como un invento del orgullo, de la hybris, y su pecado es la blasfemia, es querer ser como Dios. La Ley, por tanto, reacciona de modo violento (Hinkelammert, 1998).

En cuanto transgresor de la legalidad, Jesús resulta acusado de blasfemo y demoníaco, no sólo por parte de quienes están en el poder romano o judío, sino también por parte de muchos de sus propios seguidores que hacen parte del pueblo judío, en su mayoría jerosolimitano. La concreción de esta acusación y consecuente condena a Jesús se produce en circunstancias que permiten afirmar un "realismo político" como razón de fondo en la pasión y muerte de Jesús. Hinkelammert recoge tres circunstancias "razonables" que afirman el hecho de que Jesús fue asesinado en cumplimiento de la ley y con base a "buenas razones", esto es, aplicando criterios de realismo y racionalidad propios del punto de vista político romano y judío dominante.

1. La primera de ella tiene que ver con la provocación e incomodidad que causan las enseñanzas de Jesús en la aristocracia judía. En Jn. 11. 47-54 (BJ) los sumos sacerdotes y fariseos reaccionan y toman una decisión respecto a Jesús.

Entonces los sumos sacerdotes y los fariseos convocaron consejo y decían: "¿Qué hacemos? Porque este hombre realiza muchas señales. (48) 
Si le dejamos que siga así, todos creerán en él; vendrán los romanos y destruirán nuestro lugar Santo y nuestra nación." (49) Pero uno de ellos, llamado Caifás, que era el Sumo Sacerdote de aquel año, les dijo: "Vosotros no sabéis nada, (50) ni caéis en cuenta que es mejor que muera uno solo por el pueblo y no que perezca toda la nación." [...] (53) Desde este día, decidieron darle muerte. (54) Por eso Jesús, no andaba ya en público entre los judíos, sino que se retiró de allí a la región cercana al desierto, a una ciudad llamada Efraím, y se quedó allí con sus discípulos ${ }^{10}$.

Resulta evidente que los sumos sacerdotes y fariseos tienen miedo de lo que puedan hacerles los romanos a causa de la predicación y actos de Jesús. Reconocen el poder de convocatoria de Jesús y la potencial asunción de su mensaje por gran parte del pueblo. De modo que visualizan un resultado -una potencial adhesión masiva a Jesús, una intervención militar con destrucción del Templo y del país por parte de Roma- que sólo podría realizarse por vía de una invasión del ejército romano. De tal manera que lo que constituye el centro de su preocupación es su propia sobrevivencia: salvar su status, su nación y "su propio pellejo". Son sobrevivientes a toda prueba que,

Se ven frente a una disyuntiva extrema: o matan a Jesús o ellos mismos son matados por los romanos, junto con los lugares santos y con toda la nación judía. Es un problema de "realismo político" frente a fuerzas compulsivas de los hechos. (...) Desde el punto de vista del sentido común y del "realismo político", esta decisión es perfectamente racional. (...) La decisión de matar a Jesús no es producto de alguna rabia hacia Jesús. No es producto del "odio" ciego. La rabia no explica el hecho de que lo quieran matar. Este hecho es producto de un juicio político normal y razonable (Hinkelammert, 1998).

Asesinar a Jesús, como única salida posible en tanto no se desea "que perezca toda la nación", aparece como un argumento bien sopesado, meditado, plenamente racional y válido, que logra convencer al consejo y al Sanedrín. Desde esta perspectiva, acorde con una aproximación historizada y bíblicamente fundada, resulta evidente que los sumos sacerdotes, escribas y fariseos no estén necesariamente motivados por odios, rabias y sed de venganza, sino por la objetividad

10 Todas las citas bíblicas serán tomadas de la Biblia de Jerusalén traducida por la Escuela Bíblica de Jerusalén (Bilbao: Desclée de Brouwer, 1978). 
propia de funcionarios y estrategas de la política. Son líderes de una nación, funcionarios reconocidos y bien intencionados "de cuello blanco", que asumen la condena de Jesús con profesionalismo, con razones lógicas, con "buenas razones" para matar. Estas posturas sacerdotales y farisaicas encuentran paralelo en la descripción contemporánea weberiana del político moderno, no motivado por pasiones, iras o compromisos personales:

Sin miramiento a la persona, sine ira et studio, sin pasión y, por consiguiente, sin amor, sin arbitrio, sin gracia, como obligación profesional objetiva y no en virtud de una relación concreta personal, lleva a cabo hoy el homo politicus, al igual que el homo economicus, su misión, precisamente cuando la realiza en la medida más ideal en el sentido de las reglas racionales del moderno orden político. La justicia moderna condena hoy al delincuente a la muerte no por ira personal o sed de venganza, sino de un modo totalmente impersonal y a causa de normas $\mathrm{y}$ fines objetivos, en virtud de su propia legalidad racional inmanente (Weber, 1984).

Este criterio de "realismo político" coincide con la aplicación legalista de la ley por parte de escribas y fariseos. Los promotores de la legalidad y la vida en la polis -legalidad judía, ley imperial, etc.- acusan y condenan a muerte a Jesús, sobre la base de un criterio político: se amparan en la legalidad y tienen "buenas razones" para hacer su acusación, sentencia y ejecución. Por esto, resulta difícil personalizar la culpabilidad de la muerte de Jesús, la cual no termina recayendo ni en los romanos, ni en la aristocracia judía, ni en el pueblo. El legalismo absolutizado exige sacrificios de vidas humanas y quienes los efectúan, ciñéndose al cumplimiento de la ley, lo hacen legítima y racionalmente. La lógica sacrificialista y legalista está a la base de la propia condena a Jesús.

La ley, al ser tratada como totalizante, exige sacrificios humanos. De eso se tiene mucha constancia en los principios del cristianismo. Todos los evangelios, por ejemplo, insisten en que a Jesús se lo mata cumpliendo con la ley; en cumplimiento de la ley. Por lo tanto, no hay culpables personales de esta muerte. Es la relación con la ley la que la origina. Es bien comprensible que más tarde la teología conservadora haya preferido culpar a los judíos. Tenía que hacerlo para escapar de las consecuencias de la teología de la crítica de la ley, que era completamente incompatible con las aspiraciones del cristianismo al poder imperial (Hinkelammert, 1998). 
2. En segundo lugar, en el relato de la pasión narrado por el evangelista Juan aparece una afirmación de parte de los sumos sacerdotes que rebela la condena de Jesús según las prescripciones de la ley: "Los judíos le replicaron: 'Nosotros tenemos una Ley y según esa Ley debe morir, porque se tiene por Hijo de Dios.' Cuando oyó Pilato estas palabras, se atemorizó aún más" (19. 7s; cf. 18. 31a).

Desde el análisis aquí seguido, esta afirmación se remite al capítulo diez de Juan donde efectivamente Jesús comete tal delito: declara que todos son hijos de Dios y, por lo tanto, también él lo es. El pecado de Jesús, condenable por ley, es considerado por sus coterráneos como blasfemia. Jesús hace esta declaración en Jerusalén, dentro del Templo (Pórtico de Salomón), cuando se celebraba la fiesta de la Dedicación (Farmer, 1999) ${ }^{11}$, en el marco de una conversación con una multitud de judíos jerosolimitanos, ya no de los que han venido conformando el movimiento de Jesús o de sus simpatizantes galileos. El texto íntegro aparece en Jn. 10. 24-36:

(24) Le rodearon los judíos, y le decían: ¿Hasta cuándo vas a tenernos en vilo? Si tú eres el Cristo, dínoslo abiertamente." (25) Jesús les respondió: "Ya os he dicho, pero no me creéis. Las obras que hago en nombre de mi Padre son las que dan testimonio de mí; pero vosotros no creéis porque no sois mis ovejas. [...] (30) El Padre y yo somos una sola cosa. (31) Los judíos trajeron piedras para apedrearle. (32) Jesús les dijo: "Muchas obras buenas que vienen del Padre os he mostrado. ¿Por cuál de ellas queréis apedrearme?" (33) Le respondieron los judíos: "no queremos apedrearte por ninguna obra buena, sino por la blasfemia; porque tú, siendo hombre, te haces a ti mismo Dios." (34) Jesús les respondió: "¿No está escrito en vuestra Ley: Yo he dicho: dioses sois? (35) Si llama dioses a aquellos a quienes se dirigió la Palabra de Dios -y no puede fallar la Escritura- (36) ¿cómo decís que aquel a quien el Padre ha santificado y enviado al mundo blasfema por haber dicho: 'Yo soy Hijo de Dios'?

Jesús responde a la pregunta sobre si él es el Cristo con un resumen de lo que significa su misión, esto es, haciendo referencia a, (1) las obras que hace, que sirven como prueba de la unidad entre él y el Padre, son las mismas obras que

11 La fiesta de la dedicación o Januká conmemoraba la dedicación del Templo por los macabeos en el año 165 a.C., después de la profanación de Antíoco Epífanes (cf. 2 Mac. 10). La fiesta tenía lugar tres meses después de la Festividad de las tiendas (Sukkoth) y duraba ocho días. 
asumieran en su praxis y mensaje los patriarcas y los profetas, para cuestionar y revertir todo cuanto no afirmase el proyecto de Dios de salvación y dignificación de la vida; y (2) su condición de Hijo de Dios. Esta afirmación de Jesús de ser Hijo de Dios no resulta una respuesta común a la pregunta sobre su identidad como Mesías, dado que en la tradición judía se aplican al Mesías títulos como el de Rey de Israel, Elegido de Dios o Ungido de Dios, lo que el Jesús del Evangelio de Juan evita utilizar para autodesignarse (Mateos \& Barreto, 1980).

Contrariamente al uso judío, el título de Hijo de Dios es uno de los títulos más reconocidos del César como Emperador romano, el cual aparece en las monedas y documentos del imperio. El evangelista Juan está haciendo alusión indirecta al hecho de que la crítica de Jesús no se dirige solamente a los judíos, sino también a los romanos. Pero la diferencia de concepción de Jesús con la imagen romana del Hijo de Dios queda enseguida evidenciada.

Llama la atención la respuesta de Jesús a la acusación de blasfemia. No responde a la manera del Emperador, quien diría: Yo soy Hijo de Dios, yo soy Dios, pero ustedes no lo son. Exige a los otros postrarse frente a él. Jesús en cambio les dice a los que le reprochan querer ser Hijo de Dios: todos ustedes son dioses: "Dioses sois". Lo dice a aquellos que lo persiguen, y les insiste: eso dice "vuestra Ley". Según su propia ley tienen que reconocerse como dioses, en vez de postrarse frente a su ley (Hinkelammert, 1998).

De manera que, frente al tema de la relación filiación-paternidad para con el Padre, Jesús, como en casos anteriores, cita las propias Escrituras para demostrarles que están equivocados y que son injustos al acusarle de blasfemia. Les recuerda que efectivamente, él es Hijo de Dios, pero que no lo es solipcista y excluyentemente, sino que ellos también lo son y, que todos aquellos hijas e hijos de Dios creados a su imagen y semejanza, son dioses. Ello lo documenta con la propia ley judía en la literatura sálmica, concretamente en el Sal. 82. 6, referido al hecho de que todos los que hacen verdadera justicia al pobre son jueces (Sal, 82). Jesús ofrece una interpretación propia de este salmo, tal como lo recoge Hinkelammert:

[...] Jesús, según Juan dice esto en el "pórtico de Salomón". Salomón, como juez, es el prototipo de estos jueces. Tienen que hacer juicios "salomónicos". [...] Pero ya no son jueces algunos y otros no. Todos son jueces, en cuanto todos son dioses. Todos tienen que juzgar sobre la Ley y sus aplicaciones, no solamente aquellos en el poder, también aquellos 
que sufren el poder. Todos son jueces, todos son dioses. Tienen que ser jueces salomónicos, sin ser jueces instalados como jueces de la institución de la ley [...] Ampliando el texto desde su interior, Jesús transforma a todos en sujetos que juzgan la Ley y la interpretan, adaptan, la suspenden y la vuelven a poner (Sal 82).

Las credenciales de Jesús como Mesías, que son sus obras y su condición de Hijo de Dios, resultan universalizables en el Evangelio de Juan. Sus enseñanzas se dirigen, a mostrarse a sí mismo como el Hijo unigénito de Dios, y mediación de la relación de filiación-paternidad para la humanidad, pero abriendo esta realidad a todo aquel que asume el proyecto de salvación y humanización de Dios. En ese sentido, Jesús abre el camino para actuar y transformarse en hijos e hijas de Dios que asuman obras de dignificación de la vida; trasmite la idea de que todos deben apropiarse de una filiación y una práctica humanizadoras, dignificante y liberadoras, en la medida en que seamos capaces de recrear el proyecto de vida plena de Dios para el ser humano y el mundo.

Jesús revela de manera especial que todos son -real o potencialmente- hijos de Dios. Para el poder romano sólo el César, la autoridad imperial es Dios; para los sumos sacerdotes, escribas y fariseos solo la ley es como Dios y nadie más puede atribuirse este título. Son los únicos dioses legítimos en tanto autoridad política, económica, cultural, legal. Jesús invierte ambas posturas y niega toda legitimidad a la autoridad política, religiosa o jurídica que valga por sí y en sí misma, sin tomar en cuenta el proyecto de Dios que en él se sintetiza, revelado y encarnado en la historia humana e incluyente de cada uno de los hijos de hijas de Dios. Reivindica con ello la única autoridad que puede legitimarse: la de todos y cada uno de quienes supeditan la ley (imperial, judía) a la vida humana, acorde al proyecto de Dios. En otras palabras, reivindica y afirma teológicamente al ser humano frente a la ley, lo que ya estaba presente en su predicación sobre el Sabbaht, el templo y la ley.

Todos son dioses, todos son jueces, todos son reyes, todos son sacerdotes. Esa es la respuesta de Jesús frente a la acusación de querer ser Hijo de Dios. [...] En él, como Hijo de Dios, todos lo son. Él se presenta como Hijo de Dios en un sentido muy especial. La especialidad consiste en que él se considera Hijo de Dios en el cual todos se hacen hijos de Dios. [...] Juan insinúa una conclusión: si Dios se hizo ser humano, el ser humano se hizo Dios. [...] La forma de argumentar de Jesús, según Juan, es: 
todos ustedes son dioses, luego yo, quien vengo a revelar eso, también lo soy $(\text { Sal 82) })^{12}$.

3. La tercera y última razón que lleva a la muerte de Jesús, esbozada partir del Evangelio de Juan, proviene de Poncio Pilato, es decir, de la dominación y poder romano. En el diálogo que se establece entre el Sanedrín y Pilato, visto con anterioridad (cf. Jn. 19, 7-8), se dice que Pilato se atemoriza al escuchar de parte de las autoridades judías que, según su ley, Jesús debía morir por considerarse "Hijo de Dios". Este temor lo explica Hinkelammert por el hecho de que en la acusación a Jesús por parte de los sumos sacerdotes, hay una acusación velada al César, quien también se considera Hijo de Dios, y en nombre de quien Pilato gobierna Judea, lo que ya ha sido explicitado con anterioridad.

Esta acusación indirecta a Pilato por parte del Sanedrín tiene una contraparte en la acusación, también indirecta, que lanza Pilato a Jesús, y que implica una acusación y amenaza directa a los judíos. Esta situación está recreada en el capítulo 18 del Evangelio de Juan (33-39), una vez que Jesús es llevado al tribunal del procurador romano.

(33) Entonces Pilato entró de nuevo al pretorio y, llamando a Jesús, le preguntó: "¿Eres tú el Rey de los judíos?" (34) Respondió Jesús: "¿Dices eso por tu cuenta, o es que otros te lo han dicho de mí?" (35) Pilato respondió: "¿Es que yo soy judío? Tu pueblo y los sumos sacerdotes te han entregado a mí ¿Qué has hecho?" (36) Respondió Jesús: “Mi Reino no es de este mundo. Si mi Reino fuese de este mundo, mi gente habría combatido para que yo no fuese entregado a los judíos; pero mi Reino no es de aquí." (37) Entonces Pilato le dijo: ¿Luego tú eres Rey?" Respondió Jesús: "Sí, como dices, soy Rey. Para esto he nacido yo y para esto he venido al mundo: para dar testimonio de la verdad. Todo el que es de la verdad, escucha mi voz." (38) Le preguntó Pilato: "¿Qué es la verdad?" $\mathrm{Y}$, dicho esto, volvió a salir donde los judíos y les dijo: "Ningún delito encuentro yo en él. (39) Pero es costumbre entre vosotros que os ponga en libertad a uno por la Pascua. ¿Queréis, pues, que os ponga en libertad al Rey de los judíos?".

12 Cursivas de la autora. 
Pilato insiste en extraer de Jesús una afirmación expresa de sí como Rey de los judíos. Busca, al igual que la aristocracia sacerdotal y farisea del Sanedrín, tener de qué acusarle. Y aun cuando no logra que Jesús se autodeclare Rey de los judíos -aunque sí rey-, termina presentándolo ante el Sanedrín como "Rey de los judíos". Se trata de una acusación mentirosa evidenciada en la frase: "Ningún delito encuentro en él" (Jn 18, 38c). Es la hipocresía del poder que aparenta neutralidad e incluso, bondad, a la par que hace una declaración que, proviniendo del procurador romano y gobernador de la provincia, y por tanto, del rey de los judíos legalmente instalado, resulta una acusación grave que implica la condena a muerte por sedición y rebeldía. Pero paralelamente es posible, viable, observar aquí una acusación dirigida al Sanedrín. Pilato no acepta considerar a Jesús como un "pretendido" Rey de los judíos por cuenta propia, no legitimado por su pueblo, tal y como luego intentan aclarar los sumos sacerdotes (cf. Jn. 19, 21-22). Lo declara "Rey de los judíos" sin más, acusando y amenazando en Jesús y a través de Jesús a todos los judíos, y por extensión a quienes en las provincias romanas no aceptan y asumen obedientemente el único rey romano, el César.

Desde la lógica del poder imperial romano la acusación: "se hizo Rey de los judíos" resulta un delito de sedición, soberbia e hybris, que tiene que ser castigado con la muerte. Es el delito de quien se abroga el derecho de ponerse a la altura y rebelarse contra el poder. No importa si se trata únicamente de una pretensión, imposible de materializarse efectivamente, para el imperio significa el mismo delito, y en tanto peligro, el imperio asegura su permanencia en las provincias y su estabilidad política juzgando y ejecutando a aquellos que considera un peligro político.

Al resumir estas tres razones para la condena y muerte del Crucificado, es posible aseverar que constituyen, desde la lógica del poder dominante, "buenas razones" para matar que han sido aplicadas y legitimadas por la dominación en contra de sus adversarios. Son razones evidentes, lógicas, justas, e incluso, altruistas, por parte de quienes buscan sofocar cualquier rebelión y que se condensan en las expresiones tipológicas "mejor es que muera uno sólo y no que muramos todos", "nadie es hijo de Dios, ni Dios mismo, para ponerse a la altura de la ley, que es la única que es como Dios", "es necesario proteger la autoridad de quienes se hacen reyes por su propia voluntad". Son "buenas razones", propias del cálculo político de las instancias que ejercen un poder autoritario en todos los tiempos.

Las "buenas razones" subyacen a las lógicas del poder que procesa y sentencia a muerte a Jesús y no están regidas necesariamente por criterios de bondad 
o maldad de quienes las sostienen. De hecho, a quienes esgrimen sus "buenas razones" lógicas y bien fundamentadas para matar a Jesús, y efectivamente ejecutan su condena, Juan los presenta como hombres con grandeza. Hinkelammert recrea este hecho en relación con la figura de los sumos sacerdotes: aunque tienen rabia y miedo, frente a Pilato muestran valentía, heroísmo y dignidad -de hecho, rechazan entrar en su oficina por considerarla impura, hacen extensible la acusación a Jesús al emperador romano, como hijo de Dios, y con ello se exponen a una condena de muerte ellos mismos-. Pero este "realismo político" por su apego a la ley termina siendo falso e injusto, lo que se manifiesta y revela justamente en la muerte de Jesús.

Estas razones de la muerte muestran que a Jesús se le acusa, tortura y crucifica con amparo del legalismo. Él se rebela frente a su muerte y no acepta la injusticia de su muerte; incluso, intenta defender su causa y deja de aparecer en público, retirándose a una región desértica con sus discípulos, pero es atrapado (cf. Jn. 11. 53-54). Ello contrasta con visiones e interpretaciones tradicionales sacrificialistas de la muerte de Jesús, sea por la vía de la edulcoración y embellecimiento de la cruz o por la mística del dolor. Como plantea el autor, el autosacrificio a la manera de Sócrates ${ }^{13}$ e Ifigenia ${ }^{14}$ en la tradición griega aparece como acto heroico en la interpretación occidental tradicional; sin embargo, no expresan crítica y discernimiento del legalismo sino, al contrario, sumisión y canto a la propia muerte. En la tradición cristiana se ha intentado presentar la muerte de Jesús a la manera de la muerte de Sócrates e Ifigenia, invirtiendo así el significado de rebeldía de Jesús frente al poder que esgrime una postura de "realismo político" legalista. Como Hinkelammert destaca:

Jesús es sacrificado por la ley, pero por una ley que se cumple frente a Jesús, quien niega cumplirla y más bien la interpela en nombre de una vida para la cual ella tiene que servir. Jesús es castigado por la ley. No se sacrifica porque no acepta el juicio de la ley. Declara la ilegitimidad del cumplimiento de la ley. La ley lo sacrifica, pero Jesús no se sacrifica en el altar de la ley. También a Jesús se exige no escapar sino enfrentar

13 Referido al hecho que el filósofo acepta serenamente su condena a la pena de muerte con el método de envenenamiento suicida por cicuta, en obediencia a las leyes dictadas por el tribunal ateniense.

14 Se trata del mito griego narrado por Eurípides, según el cual el rey Agamenón sacrifica a su hija Ifigenia con el fin de apaciguar la ira de la diosa Artemisa, ganar la guerra y conquistar Troya. 
la muerte. Pero Dios no lo exige como sacrificio, sino para que sea revelado lo que es la ley, que mata al inocente en su cumplimiento. La muerte de Jesús es la catástrofe de la ley (Hinkelammert, 1998).

\section{Comentarios conclusivos}

El presente artículo ha pretendido aportar a la historización de la cruz, presentando una interpretación particular del proceso, condena y muerte en cruz de Jesús desde el llamado "realismo político", que contribuya a la comprensión y el diálogo necesario con las corrientes europeas contemporáneas de teología de la cruz, así como a la inteligibilidad del acontecimiento de la cruz desde sus referentes socio-históricos y políticos. Esta comprensión de las condiciones, motivos, circunstancias políticas del juicio, condena, tortura y ejecución del Crucificado y por tanto, de la cruz histórica que acontece como consecuencia de la opción de Dios por la encarnación, puede ayudar a superar las perspectivas tradicionales meramente sacrificiales, cultuales y dolorosas de la cruz buscando el contenido profundo de una cruz que es fundamento de la pregunta por la autenticidad de la humanización de Dios y de la fe en el Cristo crucificado-resucitado.

Atravesando el análisis descriptivo moltmanniano con la crítica a una muerte injusta efectuada en cumplimiento de un legalismo sacrificialista tipo "realismo político", salta a la vista que la muerte de Jesús no debe ser entendida en su carácter sacrificial a la manera del sacrificio judío o de las religiones precristianas desde una atribución de sentido únicamente cultual. Ella se enmarca en la praxis, la lógica y la racionalidad que rige el campo de la política conocido como "realismo político", en tanto en el entorno y circunstancias concretas de la muerte del Crucificado los intereses propios -grupales, partidarios y nacionales- de los romanos y la aristocracia judía priman sobre cualquier otra consideración de índole ética. En este sentido, la muerte de Jesús tiene desde el punto de vista histórico un carácter profano, propio de los condenados; un carácter que se evidencia en el escándalo y crudeza de la cruz de los procesados y sentenciados. La lectura bíblico-histórica que hace Theissen de los evangelios nos permite comprender el carácter político-religioso anti-legalista de la predicación de Jesús que coadyuva la condena, así como identificar los actores y motivaciones de quienes ejecutaron a Jesús, en la línea de una manipulación, estrategia y saber prudencial político antiético desde el poder político imperante. En ese sentido, "la cruz es consecuencia 
de una encarnación situada en un mundo de pecado que se revela como poder contra el Dios de Jesús" (Sobrino, 1980)15.

En el análisis que se ha venido siguiendo aquí, los actores romanos y judíos implicados en la muerte de Jesús afirman y validan de facto que "se puede matar cuando se tienen buenas razones para hacerlo". Esta es la postura que se desprende del realismo político que sostiene que es posible legitimar la muerte, siempre y cuando existan buenas razones para hacerlo. Jesús invierte esta lógica y dice que no hay ninguna razón suficientemente buena para el asesinato. Jesús afirma el "no al matar" y rechaza cualquier buena razón para una muerte injusta.

Todas las razones son malas, en cuanto el resultado es matar. Matar o no es el criterio sobre las razones, por tanto, no puede haber buenas razones para matar. Donde aparecen buenas razones, son invento del "padre de la mentira" y aquellos que las buscan, son hijos de este diablo, que es el "asesino desde los principios" y "padre de la mentira" a la vez. Pero eso precisamente es la ley. No es solamente el cuerpo legal de por sí, sino, en general, la afirmación de buenas razones para matar. La ley invierte la verdad. Mata, para que haya vida, y por eso, precisamente, desata una lógica de muerte (Sobrino, 1980).

La particularidad de la cruz histórica del Crucificado es que ella constituye el punto de diferenciación entre otras religiones y el cristianismo auténticamente evangélico; entre la superstición y la fe del Crucificado; entre la simple creencia sacrificialista y la imagen del Dios encarnado y humanado que provoca y conduce a la humanización y dignificación del ser humano; entre las lógicas y racionalidades políticas sometidas al control y reproductoras de muerte, y el principio evangélico y la ética radical de Jesús de negación de toda muerte, al margen de las "buenas razones" para efectuarla. El Jesús rechazado, maldecido y crucificado es el hombre-Ecce homo!- del skandalon que nos invita a conocer en el origen de la cruz nuestra verdad histórica y hacer "una profesión de fe que reconozca la humanidad de Dios en el Cristo deshumanizado de la cruz" (Moltmann, 2010).

15 Jon Sobrino, citado por L. Boff, op. Cit., 206. 


\section{Referencias}

Artola, A. M., (2011). La Pasiología. Roma: Editoriale Eco.

Biblia de Jerusalén. (1978). Traducción de la Escuela Bíblica de Jerusalén. Bilbao: Desclée de Brouwer.

Boff, L. (1980). Pasión de Cristo - Pasión del Mundo. Santander: Sal Terrae.

Comblin, J. (2001). “El sacrificio en la teología cristiana”, PASOS 96: 2-12.

De Mier, F. (1996). Teología de la cruz. Trípticos de las riquezas de la pasión. Madrid: San Pablo.

Farmer, W. R. (Dir.), (1999). Comentario Bíblico Internacional. Estella, Navarra: Verbo Divino.

Hinkelammert, F. (1998). El grito del sujeto. Del teatro-mundo del evangelio de Juan al perro-mundo de la globalización. San José: DEI.

Mateos, J. \& Barreto, J. (1980). Vocabulario teológico del Evangelio de Juan. Madrid: Cristiandad.

Moltmann, J. (1972). “El ‘Dios crucificado'. El moderno problema de Dios y la historia trinitaria divina", Concilium 76: 335-347.

Moltmann, J. (2010). El Dios Crucificado. La cruz de Cristo como base y crítica de la teología cristiana. Salamanca: Sígueme.

Nolan, A. (2011). “¿Quién es este hombre?”. Jesús, antes del cristianismo. Santander: Sal Terrae.

Rahner, K. (1998). Curso fundamental sobre la fe. Introducción al concepto de cristianismo. Barcelona: Herder.

Segundo, J. L. (1975). Liberación de la Teología. Buenos Aires: Carlos Lohlé.

Theissen, G. (2004). El Jesús histórico. Salamanca: Sígueme.

Weber, M. (1984). Economía y sociedad. México, D.F.: Fondo de Cultura Económica. 